\title{
Memória, museus e ciência da informação: Uma perspectiva interdisciplinar
}

\author{
Débora Adriano Sampaio, \\ Bernardina Maria Juvenal Freire de Oliveira
}

Universidade Federal da Paraíba - UFPB, Brasil

\section{ANÁLISIS}

\begin{abstract}
Resumo
Reflete sobre Museus e Ciência da Informação em uma perspectiva interdisciplinar, traçando uma interface entre memória e informação. Apresenta abordagens sócio-históricas da Ciência da Informação na tentativa de subsidiar as questões sociais que norteiam esta discussão - 'A Epistemologia Social de Shera', a 'Hermenêutica de Capurro' e a 'Abordagem do Conhecimento de Wersig'. Destaca o diálogo entre informação, memória e instituições museológicas, analisando sua importância sociocultural na dinâmica da sociedade da informação. Considera o processo de construção interdisciplinar, sob uma dimensão social, como fator imprescindível ao direcionamento de novas leituras que poderão transformar indivíduos em seres humanos críticos e reflexivos, agentes capazes de percorrer trajetos previstos e imprevisíveis, modificando a realidade social.
\end{abstract}

Palavras-chave

Ciência da Informação ; Museus ; Informação ; Memória

\section{Memory, museums and information science: An interdisciplinary perspective}

\begin{abstract}
Reflects on Museums and Information Science in an interdisciplinary perspective, tracing an interface between memory and information. Presents socio-historical approaches of Information Science in an attempt to subsidize social issues that guide this discussion - 'The Social Epistemology Shera', the 'Hermeneutics Capurro' and 'Approach of Knowledge Wersig'. Highlights the dialogue between information, memory and museum institutions, analyzing its importance in the socio-cultural dynamics of the information society. Considers the process of building interdisciplinary, under a social dimension as a vital contribution to the direction of new readings that can transform individuals in humans reflexive and critical agents capable of walking paths foreseen and unforeseen, changing social reality.
\end{abstract}

Keywords

Science ; Museums ; Information ; Memory 


\section{Introdução}

Ao refletirmos sobre Ciência da informação, podemos analisar que esta é uma disciplina científica ainda em fase de constituição, na tentativa de, com outras disciplinas, estabelecer-se, "em um período de rupturas paradigmáticas e epistemológicas, que toma características de nova, através das transformações ocorridas no decorrer do século XX". (WERSIG, 1993; GALVÃO, 1998; PINHEIRO, 1995; LOUREIRO, 1995 apud FRANCELIN, 2003, p. 65).

Neste contexto, Mattelart (2002) analisa que a informação tomou novos rumos, indo além de conservar um espírito concentrado na disponibilização e recuperação da informação, a partir dos processos de tratamento técnico, motivanos para uma reflexão mais acurada sobre as questões que circundam seus paradigmas e as discussões sobre interdisciplinaridade com outras áreas e disciplinas do conhecimento.

Edgar Morin (2002) buscou em sua obra, situar parte da produção no campo das novas concepções científicas ocorridas durante o século passado e, sobre o que interessar à área da Ciência da Informação é importante considerar estas reflexões, análises epistemológicas e paradigmáticas como uma proposta de interpretação dos fenômenos que ocorrem no mundo, o que ele denomina de "pensamento complexo". Em síntese, propõe esta complexidade referindo-se a "um conjunto de eventos, principalmente aqueles ligados à área científica, que ocorreram no final do século XIX e que foram sendo debatidos, combatidos e assimilados no decorrer do século XX" (FRANCELIN, 2003, p. 65).

Pode-se considerar que, o que houve, na realidade, foi um tipo de Revolução de quase três séculos de determinismo, de racionalismo, de univocidade, de concepção mecânica de mundo e, principalmente, da certeza que se transferia ao experimento científico; porém, tudo isso é dissipado com as descobertas da própria ciência (JAPIASSU, 1985; KUHN, 2001; EPSTEIN, 1988).

Considerando este momento, podemos citar as obras de Hilton Japiassu, com A revolução científica moderna, de 1985, Abraham Antoine Moles, com A criação científica, de 1971 e Gaston Bachelard, com A formação do espírito científico, de 1938, compreendendo que pode ser a partir de um "instintivo conservativo" que se manteve, por tanto tempo, a premissa racionalista e determinista da ciência e, mesmo com a própria ciência aceitando a imprevisibilidade do mundo, a discussão acerca dos novos paradigmas e das possíveis rupturas epistemológicas ocorridas na ciência que quase atravessou o século XX.

Existe a algum tempo, certo debate sobre as soluções que surgiram das mais diversas fontes sobre os estoques extensos de informação, quase todas propõem e realizam a facilidade de acesso a tais informações. Diversos programas foram criados voltados para a socialização informacional, a qual Francelin (2003, p. 66) caracteriza como "fundamentada em um idealismo fortuito e, por vezes, ilusório". Observa-se ainda que, parte dos cientistas da informação apoiou programas que propunham socializar a informação, isto ocorre não em nível micro, mas em macro, ou seja, o ensejo da socialização da informação embalada pela construção de grandes sociedades de informação.

Baudrillard (1994) percebe que a quantidade de informação disponibilizada não significa necessariamente socializar, pois para socializar, teria que haver reciprocidade. Desta forma, a informação, para ser socializada, precisaria ser aceita e necessária pelo e para o indivíduo e, assim, os responsáveis por este projeto de socialização, também, precisam saber se o indivíduo possui a disposição de receber a informação disponibilizada. Se isto não partir de maior esclarecimento, a informação pode continuar sendo estoque, o que, de certa maneira, mantém este instinto conservativo da ciência da informação.

Partindo dessas reflexões introdutórias, sobre as mudanças paradigmáticas e epistemológicas no campo da ciência da informação, subsidiamos a reflexão sobre a interdisciplinaridade da mesma, destacando sua a interação com as áreas de 'Memória' e 'Museu', refletindo, assim, sob esta perspectiva. 


\section{Algumas considerações sobre ciência da informação e museus}

Partindo de uma perspectiva social, neste contexto, refletirmos sobre Ciência da Informação, considerando sua determinação a partir das questões, demandas e relações sociais que constituem suas temáticas de estudo abordadas.

Almeida, Bastos e Bittencourt (2007, p. 4) afirmam que os possíveis objetos da Ciência da Informação são definidos de acordo com o grau de aproximação com os sujeitos instalados em grupos sociais:

exemplos disso estão nos estudos dedicados à organização da informação, os quais deixaram de focar as técnicas de organização para concentrar-se nos sujeitos que definem os mecanismos de organização, sua linguagem e seu modo de ver o mundo e organizar o conhecimento (ALMEIDA; BASTOS E BITTENCOURT, 2007, p. 5).

De algum modo, isto requer contribuições das diversas disciplinas das ciências sociais e humanas. Araújo (2003, p. 23) corrobora, neste sentido, refletindo que:

a Ciência da Informação é um produto da atividade humana que está sendo construído pelos agentes sociais (pesquisadores, profissionais, instituições de ensino e fomento, associações profissionais e científicas, estados e instituições multilaterais) [...].

Sendo assim, as interações sociais contribuem para confirmar esta realidade, possibilitando a troca entre os sujeitos que interagem neste processo. Berger e Luckmann (2002) analisam questões acerca da construção desta realidade, afirmando ser indispensável este interacionismo para divulgação dos conhecimentos que conferem a noção de realidade à sociedade.

Esta reflexão vai ao encontro do foco desta seção, quando sugerimos refletir sobre a relação entre Ciência da Informação e Museus, onde é possível identificá-la quando debatemos sobre os fundamentos históricos e sociais da Ciência da Informação, especificamente, ao que tange a 'Epistemologia Social de Shera' (1973), a 'Hermenêutica de Capurro' (2003) e a 'Abordagem do Conhecimento de Wersig' (1993).

A Epistemologia Social de Shera (1973) faz uma crítica à epistemologia tradicional, estabelecendo uma nova contextualização a partir do indivíduo. Ou seja, nesta abordagem, Shera estuda o conhecimento a partir do indivíduo, trazendo à tona, uma Epistemologia Social para a Ciência da Informação, formando-se um elo entre sociedade e conhecimento, dando ênfase no ser humano e na sociedade e "em todas as suas formas de pensar, agir, comunicar" (SHERA, 1973, p. 90).

Capurro (2003) reflete sobre uma concepção Hermenêutica para a Ciência da Informação, ideia, atualmente, bastante difundida entre estudiosos e pesquisadores da área. Nesta abordagem percebemos a concepção Hermenêutica construída a partir da "compreensão de um ser no mundo em relação aos outros", contrapondo a virada cognitivista que "pressuponha uma relação entre os seres, destituída de contexto, com a virada pragmática, na qual a informação ser apreendida no nosso modo de interagir com o mundo" (RENAULT; MARTINS, 2007, p. 138), apontando, assim, para uma perspectiva social, para a compreensão das relações humanas com a informação, sugerindo uma relação dialógica de interação social.

Em seguida, a Abordagem do Conhecimento apontada por Wersig (1993) pressupõe uma mudança no papel do conhecimento a partir da compreensão do outro. O discurso de Wersig (1993) considera que a Ciência da Informação deve compreender a mudança do papel do conhecimento para os indivíduos, as organizações e as culturas, que seria a grande transformação da sociedade contemporânea. Assim, Renault e Martins (2007, p. 144), sintetiza: "interessa-nos reter que a perspectiva de compreensão de como o ser humano utiliza o conhecimento consubstancia a ideia da Ciência da Informação como uma ciência da ordem das questões sociais". 
Esta perspectiva social da Ciência da Informação subsidia questões acerca da relação existente com os museus e, consequentemente, com a área de Museologia. Lima (2007, p.2) afirma que a origem dos Museus

remonta ao Mouseion, palavra grega que tem servido para designar espaço e, também, 'templo' das Musas. O registro histórico deixou marcada a indicação de um local na Grécia, colina de Hélicos (Atenas) e de outro no Egito, em Alexandria.

Estes espaços, de acordo com as reflexões de Lima (2007), consistiam em espaços que reuniam sábios da filosofia e das artes para a construção de saberes, inspirado pelas Musas, levando em consideração o poder mítico, fazendose oferendas em santuários que eram inseridos nestes locais. Neste sentido, destaca-se:

o local no qual se reuniam os membros do grupo erudito na Grécia já assinalava o que seria considerado, séculos depois, nos estudos acerca da Museologia e sua configuração. Por exemplo, os setores técnicos administrativos e de estudos dos museus (biblioteca), territórios de exibições (galerias com obras de artes e alamedas naturais) e, ainda, tipologias museológicas de classificações diversificadas (jardim botânico) incluindo-se espaços abertos (museus ao ar livre) (LIMA, 2007, p. 3).

Percebemos, então, que a Museologia como campo do saber, articula-se como geradora de conhecimento a partir dos pressupostos históricos da constituição dos Museus, dotados de acervos estabelecidos sócio-culturalmente, ao longo dos anos.

Pomian (1984 apud Lima, 2007), afirma que as relações da Museologia com outras disciplinas do conhecimento, inicialmente, tomaram como elementos referenciais os artefatos culturais ligados aos cultos e aos rituais, formadores das primeiras coleções de arte que se tem registro.

O campo da Museologia, no entanto, é representado pelo Museu, o que atualmente pode ser visto como heterogêneo, tendo em vista os objetos disseminadores da informação e dos elementos constitutivos da memória coletiva, desta forma, reconhecendo e considerando a existência da contribuição entre as disciplinas e seus mecanismos geradores de trocas,

lembrando que as contribuições interdisciplinares ocorrem em áreas de aplicação de disciplinas, motivo pelo qual essa tipologia é acolhida nos estudos do cruzamento de fronteiras do conhecimento. (LIMA, 2007, p. 6).

Portanto, a Museologia, trabalhando a partir dos Museus, subcampos como a Documentação Museológica e questões relacionadas à catalogação, indexação e recuperação da informação de acervos museológicos, estabeleceu diálogo com a área da Ciência da Informação, interagindo, neste contexto, com técnicas de outras disciplinas relacionadas, como a Biblioteconomia, a Documentação e a Computação.

Crofts (1997) aborda que, com esta interação, a necessidade de automação dos acervos foi percebida e intensificada a partir da década de 1980, com a aplicação da informática, quando ocorreu, também, o advento da internet, sendo possível a ampliação do processo informacional e de representação dos conteúdos disponíveis. Desta forma, percebe-se que as novas tecnologias de informação e comunicação estão presentes no campo contexto dos museus (LIMA, 2007).

Podemos ainda concatenar a estas ideias, o fato de que as instituições museológicas, diferente do que muitos consideram, não são instituições estáticas. Dentre as suas importantes funções, têm a responsabilidade de problematizar a história, de representar a memória de um grupo ou comunidade, através de diversas expressões culturais, visando sua preservação. Devendo, com certa urgência, cada vez mais trilhar os caminhos da memória, expô-la, problematizá-la, a fim de estabelecer um diálogo com a sociedade. 
Considerando esta dinâmica interdisciplinar podemos desenvolver sentidos amplos e diversificados que revelam o enfoque da noção de interdisciplinaridade abordada, numa perspectiva social e cultural estabelecida e consolidada.

\section{A interface: informação, memória e museus}

Entende-se por memória a capacidade que o ser humano apresenta de reter os fatos e experiências vivenciadas no passado e transmiti-los às novas gerações através de diferentes suportes como a voz, a música, imagens, objetos, livros, entre outros. "A memória, portanto, representa a conservação de informações individuais ou coletivas de determinados fatos, acontecimentos, situações, reelaborados constantemente” (LE GOFF, 2003, p. 423).

Em geral, ao falarmos em memória, nos referimos, inicialmente, à capacidade de lembrar o que foi vivido. De um modo geral, todos nós construímos memória ao longo do tempo, a partir de acontecimentos do nosso cotidiano que podem ser evidenciados, tanto nas coisas que realizamos ou não, pois muitas vezes, lembramos de fatos que nem sequer vivenciamos, mas que foram importantes na construção da memória de uma região, de um povo, como por exemplo, os acontecimentos históricos e políticos. Somos atores sociais, ativos e indispensáveis na construção da memória individual, mas, sobretudo, da memória coletiva que deve ser entendida em âmbito social e que está sujeita a transformações constantes.

Montenegro (1994) reflete que a questão da memória e suas alterações, face aos novos modos de vida do presente, tem sido intensamente discutidas: a concepção de memória, embora considerada em uma perspectiva histórica, está marcada, também, pelo caráter livre, onde lembrar não é reviver, mas refazer, repensar, com ideias de hoje as experiências do passado. A memória é um recurso interno do ser individual ou coletivo, que vem à tona para lhe mostrar a sua identidade. No "túnel do tempo", revisitado pela memória, encontra-se toda a herança cultural do ser humano. Para que o processo de construção de uma identidade seja pessoal ou coletiva, a memória torna-se um recurso primordial.

Parafraseando Nora (1993), podemos refletir que a acentuada fragmentação da vida coletiva e a crescente valorização dos indivíduos na sociedade contemporânea resultaram na desvalorização dos "laços de continuidade" em várias sociedades, surgindo, desta forma, a necessidade de se promover espaços para a preservação e construção de memórias, que antes eram construídas pelos grupos sociais, sendo instaurada uma memória coletiva, valorizando os vínculos grupais, transformados pela história, frutos de vestígios que sobrevivem ao tempo.

A modernização, cada vez mais acentuada, do capitalismo implica destruição de valores concretos. Para se contrapor a isto é preciso um processo de revalorização, a fim de selecionar, nomear, transmitir e preservar a memória, o passado.

É necessária, então, uma recuperação, no sentido de preservar a memória e representá-la na busca por uma identidade social. A sua não-preservação leva, às sociedades, ao esquecimento e, portanto, a perdas de informações passadas. Ao encontro desta reflexão, Jeudy (1990) afirma que, assim como todo indivíduo viveria mal sem memória, também a coletividade precisa de uma representação constante do seu passado.

A partir destas reflexões acrescentamos que os museus, neste processo, fornecem subsídios para a preservação da informação memorialística, apresentando-se como guardiões e disseminadores dessas memórias.

Nestes espaços, é possível perceber a ampla e variada gama de informações contidas nos objetos, representações e expressões da memória coletiva que demonstram complexidades específicas, caracterizadas simbolicamente num itinerário de descobertas feitas por uma comunidade específica na busca por uma construção identitária.

Assim, esta interface proposta entre informação, memória e museu orienta e fortalece as contribuições interdisciplinares do campo da Ciência da Informação. Pode-se dizer que este caráter interdisciplinar, pautado no diálogo e interação com as mais diversas áreas do conhecimento, é fundamental para a construção e rediscussão de abordagens e paradigmas entre os pesquisadores e demais estudiosos, não somente na área da Ciência da Informação, mas entre as áreas que traçam pontes e percorrem trajetos em busca de maior entendimento e descobertas de novos horizontes. 


\section{Reflexões finais}

Apesar da multiplicidade de fatores envolvidos, a área da Ciência da Informação encontra-se num importante processo de consolidação interdisciplinar com as mais diversas áreas do conhecimento. A Ciência da Informação, portanto, é uma área que se desdobra dos conceitos introdutórios e gerais de 'ciência' e 'informação', termos com muitas definições concorrentes.

Consideramos a importância desta reflexão para as Ciências Humanas, Sociais e Sociais Aplicadas. Pois, todo esse processo de construção e perspectiva interdisciplinar requer conhecimentos, que só poderão ser rediscutidas a partir de leituras que transformarão indivíduos em seres humanos críticos e reflexivos, agentes capazes de percorrer caminhos previstos e imprevistos modificando, assim, a realidade social.

Ao que se refere às dimensões do assunto, esta reflexão não pretendeu uma cobertura mais abrangente, pois é, antes, uma abordagem preliminar dos temas centrais ligados entre si, que fundamentam, teoricamente, esta abordagem. A sua importância consiste em analisar e identificar a representação das informações passadas no espaço do Museu, contribuindo para o enriquecimento e consolidação das concepções de memória, norteadas pelas concepções de informação, agindo e interagindo dentro de um mesmo universo, podendo ser debatidas da mesma maneira, mas por apresentar suas especificidades, devem ser trabalhadas e refletidas levando-se em consideração seus próprios pressupostos. Por isso tratamos de reunir conceitos, conhecer abordagens e verificamos os paralelos existentes para traduzirmos o diálogo existente que, algumas vezes, tem provocado interpretações superficiais.

Buscamos construir um novo olhar, de redescobrir o que possui a Ciência da Informação, enquanto arcabouço teórico, explorando abordagens fundamentais para o estabelecimento desta construção interdisciplinar. Nesta dinâmica está a interação dos fatos, que se integram e formam unidades cada vez maiores, assim, conduzemnos para mudanças e mostra-nos a interdependência dos seres humanos e instituições que são capazes de transformar as configurações da sociedade atual.

Pretendemos contribuir com as reflexões já existentes acerca da interdisciplinaridade da Ciência da Informação com outras áreas, construindo uma interface entre informação e memória, haja vista o impulso e a importância do assunto para as instituições museológicas.

Com base nesta reflexão, torna-se indispensável visualizarmos as instituições museológicas como um espaço dinâmico de construções, reconstruções e representações da memória, fonte de informação indispensável para a sociedade em âmbitos culturais e educacionais, tendo por papel social a construção de mentalidades críticas e conscientes dos seus valores e de seu espaço de vivência, atuando como agentes de transformação social.

\section{Bibliografía}

ALMEIDA, Carlos Cândido de; BASTOS, Flávia M.; BITTENCOURT, Fernando. Uma leitura dos fundamentos histórico-sociais da Ciência da Informação. Revista Eletrônica Informação e Cognição, v. 6, n. 1, p. 68-89, 2007.

ARAÚJO, Carlos Alberto Ávila. A ciência da informação como ciência social. Ciência da Informação, v. 32, n. 3, p. 21-27, set./dez. 2003.

BACHELARD, Gaston. A formação do espírito científico. Rio de Janeiro: Contraponto, 2001.

BAUDRILLARD, Jean . À sombra das maiorias silenciosas: o fim do social e o surgimento das massas. 4. ed. São Paulo : Brasiliense, 1994.

CAPURRO, Rafael. Epistemologia e ciência da informação. In: V. ENCONTRO NACIONAL DE PESQUISA EM CIÊNCIA DA INFORMAÇÃO, 5. Belo Horizonte, 2003. Anais... Escola de Ciência da informação da UFMG, 2003.

CROFTS, Nick. Réflexionssurl'impact de latechnologie de l'informationsurlaqualité de ladocumentationmuséologique. ColofhonCIDOC Bulletin - Comité InternationalpourlaDocumentation, Anvers (Antwerp):

KoninklijkMuseumvoorSchoneKunsten. v. 8, aôut 1997, p. 33-38.

EPSTEIN, Isaac. Revoluções científicas. São Paulo: Ática, 1988. 
FRANCELIN, Merivalde Moacir. A epistemologia e a complexidade da Ciência da Informação. Ciência da Informação, Brasília, v. 32, n.2, p. 64-68, mai./ago. 2003.

GALVÃO, Maria Cristiane Barbosa. Construção de conceitos no campo da ciência da informação. Ciência da Informação, Brasília, v. 27, n. 1, p. 46-52, jan./abr. 1998.

JAPIASSU, Hilton. A representação do conhecimento e o conhecimento da representação: algumas questões epistemológicas. Ciência da Informação, Brasília, v. 22, n. 3, p. 217-222, set./dez. 1993.

A revolução científica moderna. Rio de Janeiro: Imago, 1985.

JEUDY, Henri-Pierre. Memórias do social. Rio de Janeiro: Forense Universitária, 1990. (Coleção Ensaio e Teoria).

KUHN, Thomas S. A estrutura das revoluções científicas. 6. ed. São paulo: Perspectiva, 2001.

LE GOFF, Jacques. História e memória. Campinas: UNICAMP, 2003.

LIMA, Diana Farjalla Correia. ENANCIB - Encontro Nacional de Pesquisa em Ciência da Informação, 8, 2007, Salvador. Anais eletrônicos... Salvador, 2007. Disponível em: <http://www.ancib.org.br/anais>. Acesso em: 10 mai. 2010.

MATTELART, Armand. História da sociedade da informação. São Paulo : Loyola, 2002.

MOLES, Abraham Antoine. A criação científica. São Paulo: Perspectiva, 1971.

MONTENEGRO, Antônio Torres. História oral e memória. São Paulo: Contexto, 1994. (Coleção Caminhos da História).

MORIN, Edgar. A cabeça bem feita: repensar a reforma, reformar o pensamento. 6. ed. Rio de Janeiro : Bertrand Brasil, 2002.

NORA, Pierre. Entre Memória e História: a problemática dos lugares. In: Projeto História. São Paulo: PUC, n. 10, pp. 07-28, dezembro de 1993.

PINHEIRO, L. V. R; LOUREIRO, J. M. M. Traçados e limites da ciência da informação. Ciência da Informação, Brasília, v. 24, n. 1, p. 42-53, jan./abr. 1995.

POMIAN, Krzysztof. Colecção. In: LE GOFF, Jacques. (Coord). Memória e história. Lisboa: Imprensa Nacional, Casa da Moeda, 1984. p. 51-83. (Enciclopédia Einaudi, 1).

RENAULT, Leonardo Vasconcelos; MARTINS, Ronaldo. O retrato da Ciência da Informação: uma análise de seus fundamentos sociais. Revista Eletrônica de Ciência da Informação, n. 23, 1ํㅗ. sem. 2007.

SHERA, Jesse. Epistemologia social, semântica geral e biblioteconomia. Ciência da Informação, Rio de Janeiro, v. 2, n. 2, p. 8797, 1973.

WERSIG, G. Ciência da informação: o estudo do conhecimento na pós-modernidade, Information Processing \& Management, v. 29, p. 229-239, 1993. 


\section{Dados das autoras}

\section{Débora Adriano Sampaio}

Bacharel em Biblioteconomia pela Universidade Federal do Ceará (2006), Mestre em Ciência da Informação pela Universidade Federal da Paraíba (2011). Professora da Universidade Federal do Ceará - Campus Cariri, no curso de Biblioteconomia, atuando no setor de estudos \&quot;Organização e Tratamento da Informação\&quot;. Desenvolve estudos e pesquisa sob as seguintes temáticas: organização, representação da informação, memória, patrimônio e identidade cultural.

deborasampaio13@yahoo.com.br

\section{Bernardina Maria Juvenal Freire de Oliveira}

Doutora em Letras pela Universidade Federal da Paraíba (2009), mestre em Ciência da Informação pela Universidade Federal da Paraíba (1999), Especialista em Organização de Arquivos, Especialista em Administração da Educação a Distância, graduação em Biblioteconomia pela Universidade Federal da Paraíba (1988). Professora adjunta da Universidade Federal da Paraíba. Coordenadora do Programa de Pós-graduação em Ciência da Informação da Universidade Federal da Paraíba. Na pós-graduação leciona a disciplina Memória e Identidade. Professora dos Cursos de Graduação em Arquivologia e Biblioteconomia. Experiência na área de História cultural e memória, com ênfase na produção e circulação de suportes de leitura. Na pós-graduação atua nas seguintes temáticas: Informação, memória e patrimônio cultural; Arquivo, memória e identidade; Cultura material e memória; Escrita de si; Redes sociais e Memória literária. Na graduação é professora de Representação Descritiva da Informação Arquivística, História da Leitura e dos Registros do Conhecimento.

bernardinafreire@yahoo.com.br

Recebido-Received : 2013-06-28

Aceito - Accepted : :2013-09-27

\section{(c) $\mathbf{E Y}$ New articles in this journal are licensed under a Creative Commons Attribution 3.0} United States License.

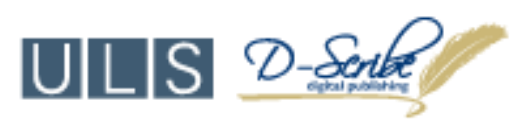

This journal is published by the University Library System of the University of Pittsburgh as part of its D-Scribe Digital Publishing Program and is cosponsored by the University of Pittsburgh Press. 